\title{
Future avenues and challenges of exploring complex personhood
}

The objective of this reflective piece is to offer an account of our personal experiences of being involved with the journal of Qualitative Research in Organizations and Management, to review the themes and issues stemming from our work that we think most pertinent, and to highlight those topics that we consider to contain the greatest future promise and potential.

A core focus vital to the work of this journal is nicely encapsulated in Gordon's (2008) notion of 'complex personhood'. Essentially, Gordon's term refers to an understanding of personhood that captures how people's lives are full of enormously subtle meanings, contradictions, and incongruities, and to the complex facets of recognition and misrecognition of people, both by themselves and others. An engagement with this complexity of personhood finds expression in a multiplicity of forms of interest and regard from researchers. It underpins vigorous debates related to such issues as: interpretive forms and norms of knowledge production; reflexivity in research practice; participants' involvement in the research process and the co-production of knowledge; and the negotiation of power relations in empirical investigation.

Engagement with the journal prompted our own consideration of novel and traditional methodological tools and procedures in a number of different ways. To name a few, we considered the challenges of empirically accommodating the material and embodied aspects of organisational practices; investigating the unspoken; and accessing hard-to-reach groups. In relation to the latter, this involved working with participants who were typically not accustomed to talk centring on selfdisclosure, and who were evidentially constrained by their own assumptions associated with social positioning: holding back on revelation and self-reflection, sometimes remaining entirely silent on certain issues. It was a concern with the epistemological importance of rapport in social scientific inquiry that ultimately underpinned our participation in the special issue 'Doing Dirty Research' edited by Grandy, Mavin and Simpson (2014). Our own recent research on working class men doing 'dirty work' made it apparent that fear of negative evaluation and participants' suspicion of 
researchers' motives, restricted and limited verbal exchanges initially leaving more contentious issues undiscussed. We also experienced participants' confusion regarding our interest in them as researchers. It became noticeable in our research that there was a pre-sentiment among participants that their voices were not going to be heard, even if they shared their views and feelings via the research. The encounter with participants' unwillingness to open up made us reconsider traditional approaches to interviewing. It prompted us to explore, for example, how the use of ethnographic observations and field notes can help document the expression and social significance of the unattractive sentiments attached to dirty work occupations. In designing the research project, we consulted a number of publications that have proven indispensable in our choice of research sites, making decisions on the timing of our investigations, and implementing critically reflexive ethnographic research practices (see Pritchard, 2011; Lambotte and Meunier, 2013). However, we feel that numerous issues remain. In particular, there is still room for a more detailed discussion of the complex dynamics involved in the process of establishing rapport - perhaps a topic for future issues of the journal? What, for example, is the role of diversions and 'off-topic' conversations in rapport-building? What is the relevance of post-interview conversations, and what procedures could be used to capture them? Under what circumstances is it appropriate to express empathy with participants, and what means of expression are available to researchers?

Our experiences of research also highlighted the difficulties of empirically accessing emotion. Researching emotions (in particular, negative emotions) can be a problematic task in two ways: firstly, researchers typically rely on verbal reports as a 'proxy' for the actual emotional states that subjects experience or intend to project (Höpfl and Linstead, 1993); and secondly, there is normative pressure on certain groups to disengage with their emotions as they characteristically understand themselves as non-emotional and self-restrained, and indeed hold a restraint of emotional expression as a behavioural ideal (Lewis and Simpson, 2007). The complications of capturing emotions prompted our interest in visual methods. We were particularly enthralled by the journal's efforts to discuss how 'the visual' might be conceptualised more broadly as a useful development 
and extension of qualitative research strategies. The special issue 'Exploring the visual in organizations and management' edited by Jane Davison, Christine McLean and Samantha Warren attracted us as to explore how visual methods (in particular, the use of photographic images) can facilitate exposing layers of experience that cannot be easily accessed by verbal means alone. The conversation in the special issue critically examined how images could be produced and used as a part of enhancing the investigative potential of qualitative methods. However, further discussion on the use of visuals would be welcome. For example, more attention could be paid to the actual process of co-constructing meanings of non-verbal and verbal interactions, including the thorny issue of whether images are in need of text to 'fix' their hermeneutic specificity. This is particularly the case for video (see, for example, Rose 2011). The development of affordable, portable digital film technology and editing software has led to an increasing use of video-based studies of work practice in sociology, humanities, education, health studies, consumer research and, to a lesser extent, organisation and management studies (Clarke, 2011; Hindmarsh \& Tutt, 2012; Spencer, 2011). The studies that are available, excellent as they are, offer relatively little in terms of attending to the practices and practicalities of exploiting video-based methods in organisational research projects. The growing discussion on how organizational researchers might take materiality more seriously in their empirical studies (Scott and Orlikowski , 2014) will sooner or later raise questions concerning methodological issues associated with the attempts to document material dimensions of organizational practices. The use of films and video-based methods would thus be another exciting avenue for the journal to explore.

The field has also witnessed an increased interest in novel forms of theorisation and conceptualisation. Scholars have been looking for means by which to bridge the divide between the mind and the body, to transgress presentational and non-presentational boundaries, and to provide a new vocabulary and a wider range of analytics for the understanding of organisational life. This search has stimulated an engagement with such concepts as the 'uncanny', the corporeal, and has more generally promoted a turn towards sensuous modalities. However, studies of this vein rarely 
engage with contemporary methodological concerns related to this novel form of theorisation. The task of undertaking such research presents researchers with unique methodological opportunities and dilemmas. The journal might want to continue the discussion developed by Sam Warren (2012) who prompts us to look into methodological challenges of adopting a psychoanalytical perspective in organizational research.

In the journal, the discussion of innovative methods has been combined with perennial concerns related to quality in qualitative research. A lot of effort has been spent by contributors to offer guidance to qualitative researchers in improving or judging the 'worth' of their research. However, it is arguable that methodological concerns principally get resolved in the process of actually doing research: pursuing hunches, dealing with confusion, and confronting doubt, rather than via the decontextualized and empirically divorced consideration of epistemological and methodological debates. It is important, in our opinion, to address the issues identified in the exciting special issue edited by Donnelly, Gabriel and Ozkazanc-Pan (2013) on the messiness of the research process - of approaches that failed to work and tools that actually hindered the process of generating rich data. For example, one area that invites further reflection is how to register doubt, cultivate hunches, and attend to surprises. It might be fruitful to reflect upon the importance of pursuing what may be initially only present in the research encounter as vaguely felt notions (Hopper and Quiñones, 2012). Presenting data is often accompanied by the sense that something might be omitted or even misrepresented in writing. This feeling might emanate from observing non-verbal interactions, the unspoken; from witnessing daily practices and exchanges; or from being present in situations that might be symptomatic of uncaptured complexity. For example, in our own research project on dirty work, there was a feeling that during interviews the process of rationalisation took over and replaced the recounting of lived experiences. Verbal exchanges were sometimes more revealing of the pressures of normative expectations and the need to adhere to identity-affirming norms than they were of the topics discussed. In our study of street cleaners, participants unanimously insisted that they liked their job. They were typically willing to engage with discussions that opened up 
possibilities for the construction of valued identities - for example, conversations which encouraged a display of masculinity through the demonstration of strength and endurance - but more reluctant to acknowledge the injuries of devaluation. The role of surprises in research remains particularly under-explored. For example, Czarniawska (1999) is intrigued by the amount of mystery which can be detected in the research process. Alvesson and Karreman (2007) draw attention to the search for 'the unanticipated and unexpected' and to the process of breakdown through which mystery could be potentially approached. All these scholars advocate 'the living state of doubt', and highlight the implication of everyday imaginative work which drives researchers to generate possibilities; try them out; modify, transform, or abandon them; try again; and so on until new concepts or patterns are generated that productively satisfy our doubt (Locke et al, 2008). Doubt is a crucial part of any research process - the question is not whether, but how to engage doubt. How might doubt be cultivated? It might also mean finding a way of being lost or losing one's direction.

In the discussion of the richness of qualitative data it would be useful to assess the potential of not just several methods combined together but also of what Fujii (2010) describes as working with meta-data (images, interviews, field notes, and participant observation). For Fujii (2010), meta-data emerges when researchers register respondents' spoken and unspoken (embodied) interactions interactions that are not always articulated in respondents' narratives or interview responses. Further discussion of the challenges and benefits of using multiple qualitative data sets might be welcome by researchers. Also of potential interest for the future is how the links between quality and advocacy can be strengthened. As is the case when bidding for funding, researchers are expected to demonstrate that research findings can translate into tangible benefits for individuals and/or organizations and wider society. It is relevant to reflect upon what might be understood as 'meaningful qualitative research' (Amis and Silk, 2008), and what alternative forms of reporting might be available and how forms of assessment might change. For example, Amis and Silk (2008) suggest considering such concepts as detail, emotion, and nuance in research assessment. Goodall (2010) talks about failure to tell a convincing story or more precisely a story that is capable of 
capturing public imagination and steering public political will. The question which remains largely unanswered is how to combine the appeal to a public imagination with the need to adhere to a particular format of reporting. Following from this concern, we might consider the extent to which methodological developments in empirical investigation necessitate a tolerance for alternative forms of expression. Might the boundaries between science and rhetoric be redefined as a consequence of such a process? Will the pressure remain to adhere to the accepted norms of the field? Will there be room for new modes of expression, for example, there is emerging literature on the use of collaborative documentaries as possible research outcomes? Again, in relation to visual research, might imagery become acceptable not simply as a means by which to access data, but as itself the principle vehicle for the expression of concepts, ideas and knowledge?

Questions such as these challenge deeply ingrained assumptions about the process of research and its 'reporting' in academic journals. More generally, the questions pursued in this journal are prompting a rethink of what qualitative research entails, how it might be assessed and evaluated, how it might be extended and reimagined, and of its enduring value to the development of knowledge about organisations and management. As we have suggested above, there remains much to explore further. It is our express hope that this journal remains a primary platform for discussion of the development of innovations within, and extensions of, existing paradigms in organisational research.

\section{References}

Alvesson, M. and Kärreman, D. (2007), "Constructing mystery: Empirical matters in theory, development", Academy of Management Review, Vol. 32, No. 4, pp. 1265-1281.

Amis, J. M., and Silk, M. L. (2008), "The philosophy and politics of quality in qualitative organizational research", Organizational Research Methods, Vol. 11, pp. 456-480. 
Clarke, J. (2011), "Revitalizing entrepreneurship: How visual symbols are used in entrepreneurial performances", Journal of Management Studies, Vol. 48, pp. 1365-1391.

Czarniawska, B. (1999), Writing Management: Organization Theory as a Literary Genre, University Press, Oxford.

Donnelly, P., Gabriel, Y and Özkazanç-Pan, B. (2013), "Untold stories of the field and beyond: narrating the chaos", Qualitative Research in Organizations and Management: An International Journal, Vol. 8, No.1, pp. 4 - 15.

Fujii, L. A. (2010), "Shades of Truth and Lies: Interpreting Testimonials of War and Violence", Journal of Peace and Research, Vol. 47, No. 2, pp. 231-241.

Goodall, H. L. (2010), "From tales of the field to tales of the future", Organizational Research Methods, Vol. 13, pp. 256-267.

Gordon, A. (2008), "Ghostly Matters: Haunting and the Sociological Imagination", University of Minnesota Press, Minneapolis, MN.

Hindmarsh, J. and Tutt, D. (2012), "Video in analytic practice", in S. Pink (Ed.) Advances in visual methodology, Sage, London, pp. 57-72.

Hopper, J. M. and Quiñones, S. (2012), "A Hunch Without a Sound: Co-constructing Meaning of Nonverbal Interactions in Video Data", International Journal of Qualitative Methods, Vol. 11, No. 5, pp. 547-572.

Höpfl, H., and Linstead, S. (1993), "Passion and performance: suffering and the carrying of organizational roles", In S. Fineman (ed.) Emotions in Organizations, Sage, London, pp. 76-93.

Koning, J. and Ooi, C.S. (2013), "Awkward encounters and ethnography", Qualitative Research in Organizations and Management: An International Journal, Vol. 8, No. 2, pp. 16-32.

Lambotte, F., and Meunier D., (2013), "From bricolage to thickness: making the most of the messiness of research narratives", Qualitative Research in Organizations and Management: An International Journal, Vol. 8, No. 1, pp. $85-100$. 
Locke, K., Golden-Biddle, K. and Feldman, M.S. (2008), "Making doubt generative: Rethinking the role of doubt in the research process", Organization Science, Vol. 19, No. 6, pp. 907-918.

Lewis, P. and Simpson, R. (2007), Gendering emotions in organization, Palgrave, Basingstoke.

Pritchard, K (2011), "From "being there" to "being [...] where?": relocating ethnography", Qualitative Research in Organizations and Management: An International Journal, Vol. 6, No. 3, pp.230 - 245.

Rose, G. (2011), Visual Methodology: An Introduction to Researching with Visual Materials, Sage, London.

Scott, S. V. and Orlikowski, W. J. (2014), "Entanglements in Practice: Performing Anonymity Through Social Media", MIS Quarterly, Vol. 38, No. 3, pp. 873-893.

Spencer, S. (2011), Visual research methods in the social sciences, Routledge, New York, NY.

Warren, S. (2012), "Psychoanalysis, collective viewing and the "social photo matrix" in organizational research", Qualitative Research in Organizations and Management: An International Journal, Vol. 7, No.1, pp. 86-104. 